\title{
Experimental determination of the phase function and degree of linear polarization of El Chichón and Pinatubo volcanic ashes
}

\author{
O. Muñoz, ${ }^{1}$ H. Volten, J. F. de Haan, W. Vassen and J. W. Hovenier ${ }^{2}$ \\ Department of Physics and Astronomy, Free University, Amsterdam, Netherlands
}

Received 25 June 2001; revised 18 September 2001; accepted 20 September 2001; published 10 July 2002.

[1] We present measurements of the phase function and degree of linear polarization for unpolarized incident light as a function of the scattering angle for El Chichón and Pinatubo volcanic ashes at $633 \mathrm{~nm}$. The results are combined and compared with those for Pinatubo at $442 \mathrm{~nm}$ and Lokon volcanic ash at 442 and $633 \mathrm{~nm}$ [Volten et al., 2001]. The three samples of volcanic ashes consist of micron sized, irregularly shaped particles in random orientation. The results are presented in the form of figures and tables for all three samples. Similarities and differences between the results for the three samples are discussed. The measured phase functions and angular distributions of the polarization can be used to evaluate models used to calculate scattering properties of volcanic ash particles, to constrain scattering properties of volcanic ashes used in radiative transfer calculations, and to retrieve characteristics of (clouds of) volcanic ash particles in the atmosphere from remote sensing data. INDEX TERMS: 0305 Atmospheric Composition and Structure: Aerosols and particles (0345, 4801); 0343 Atmospheric Composition and Structure: Planetary atmospheres (5405, 5407, 5409, 5704, 5705, 5707); 0360 Atmospheric Composition and Structure: Transmission and scattering of radiation; 0669 Electromagnetics: Scattering and diffraction; KEYWORDS: Aerosols and particles, planetary atmospheres, transmission and scattering of radiation, scattering and diffraction

\section{Introduction}

[2] Volcanic eruptions inject into the atmosphere active gases and solid aerosol particles. If a volcanic eruption is strong enough, it will eject ash and debris into the stratosphere, which remain there for months to several years. This will change the composition of the stratosphere, which will affect the Earth's radiation budget [Oberbeck et al., 1983; Snetsinger et al., 1987; Lambert et al., 1993; Pueschel et al., 1994; Tsitas and Yung, 1996]. Stratospheric volcanic aerosols are of two general types: silicate ash produced directly at the time of the explosion and sulfate aerosols. After a volcanic eruption, the $\mathrm{SO}_{2}$ injected into the atmosphere is transformed into $\mathrm{H}_{2} \mathrm{SO}_{4}$, and subsequently, the acid vapor condenses on existing particles or forms new particles. The silicate aerosol has its greatest relative importance in the months immediately after an eruption, while in later months the sulfate aerosol is of relatively greater importance. In this work we will focus on the silicate ash particles.

[3] Climate impacts of volcanic aerosols are well established [see, e.g., Pollack et al., 1976; Hansen et al., 1978; Pollack and Ackerman, 1983; Kondratyev, 1988; Stenchikov et al., 1998], and some analyses indicate that the composition and size distribution of the aerosols can

\footnotetext{
${ }^{1}$ Now at Instituto de Astrofísica de Andalucía, CSIC, P.O. Box 3004 Granada, 18080, Spain.

${ }^{2}$ Also at Astronomical Institute Anton Pannekoek, University of Amsterdam, Kruislaan 403, NL-1098 SJ Amsterdam, Netherlands.

Copyright 2002 by the American Geophysical Union. 0148-0227/02/2001JD000983\$09.00
}

significantly affect the climate changes [see, e.g., Hansen et al., 1992]. In order to study the global distribution of atmospheric ash particles and their radiative impact, the retrieval of the optical thickness of the volcanic aerosols plays a key role. For that purpose, certain properties of the aerosols need to be known or estimated, like their phase (scattering) function. This holds, for instance, when satellite radiometers are used which measure the intensity (radiance) of the reflected light in one or more directions and wavelength bands [see, e.g., Rao et al., 1988; Lambert et al., 1993; Wang and Gordon, 1994; Wen and Rose, 1994; Krotkov et al., 1997; Mishchenko et al., 1999]. When not only the intensity but also the polarization of the reflected light is measured simultaneously, retrievals of aerosol characteristics can be significantly improved [see, e.g., Herman et al., 1997; Mishchenko and Travis, 1997a; Mishchenko and Travis, 1997b; Bréon et al., 1997; Goloub et al., 1999; Chowdhary et al., 2001]. For both types of measurement, however, accurate retrieval of aerosol characteristics is usually hampered by lack of information on the scattering properties of realistically shaped aerosols. This holds in particular for their phase function and angular distribution of the polarization of singly scattered light for incident unpolarized light.

[4] Volcanic ash clouds formed right after the eruption are especially dangerous to modern aircraft. Jet engines are affected by volcanic ash particles, and these can also produce acid abrasion of windshields and other surfaces [Rose, 1986; Bernard and Rose, 1990]. On-board radar systems cannot detect volcanic clouds because of the small size of volcanic ash particles, and visual detection of these 
clouds is very difficult. Therefore remotely sensed measurements made by orbiting satellites are highly useful for directly mapping the positions of volcanic ash clouds. Remote sensing can also be used to improve cloud trajectory models by providing frequently updated information on the mass estimates and the position of the clouds of volcanic ashes [Krueger et al., 1995; Rose and Schneider, 1996; Schneider et al., 1999; Krotkov et al., 1999a]. For that purpose, the phase function and single-scattering albedo are needed.

[5] For homogeneous spherical particles, one can use Lorenz-Mie theory [Mie, 1908] to accurately compute their single-scattering and absorption properties. However, when this theory is used for irregular mineral particles, it may lead to large errors for aerosol remote sensing and climate modeling [see, e.g., Lacis and Mishchenko, 1995; Mishchenko et al., 1995; Krotkov et al., 1999b]. Other theoretical approaches are at present available for computing the single-scattering and absorption behavior of nonspherical particles [see, e.g., Mishchenko et al., 2000a], but it has not been demonstrated that any of these can adequately represent the characteristics of volcanic ash particles [see, e.g., Oberbeck et al., 1983; Sheridan et al., 1992; Krotkov et al., 1999b; Volten et al., 2001]. Consequently, experimental studies of the scattering behavior of different volcanic ashes are very important for satellite retrievals of aerosol characteristics, climate modeling, and detecting and tracking of volcanic ash clouds. However, only a very small number of laboratory measurements of the scattering behavior of volcanic ashes have been reported in the literature [Winchester et al., 1981; Volten et al., 2001].

[6] Volten et al. [2001] present laboratory measurements of complete scattering matrices as functions of the scattering angle in the range from $5^{\circ}$ to $173^{\circ}$, of seven different samples of randomly oriented mineral particles (including Pinatubo and Lokon volcanic ashes) at two different wavelengths, 442 and $633 \mathrm{~nm}$. In this work we present unique measured results of the phase function and degree of linear polarization for unpolarized incident light as functions of the scattering angle in the range $5^{\circ}-173^{\circ}$ for El Chichón volcanic ash at $633 \mathrm{~nm}$. The measurements could not be repeated at $442 \mathrm{~nm}$ due to the limited amount of sample. We also present new results of measurements for Pinatubo volcanic ash at $633 \mathrm{~nm}$. The results are combined and compared to those obtained by Volten et al. [2001] for Pinatubo ash at $442 \mathrm{~nm}$ and for Lokon volcanic ash at both wavelengths.

[7] In section 2, we present a brief review of the basic scattering definitions and a description of the measurements approach, while section 3 summarizes the physical characteristics of our volcanic ash samples. Results and a discussion of our experiments are given in section 4 .

\section{Some Concepts of Light Scattering and the Experimental Setup}

[8] The flux and polarization of a quasi-monochromatic beam of light can be represented by a column vector $\mathbf{I}=\{I$, $Q, U, V\}$, also called Stokes vector [Van de Hulst, 1957; Hovenier and van der Mee, 1983]. Here, $I$ is proportional to the total flux of the beam. The Stokes parameters $Q$ and $U$ represent differences between two components of the flux

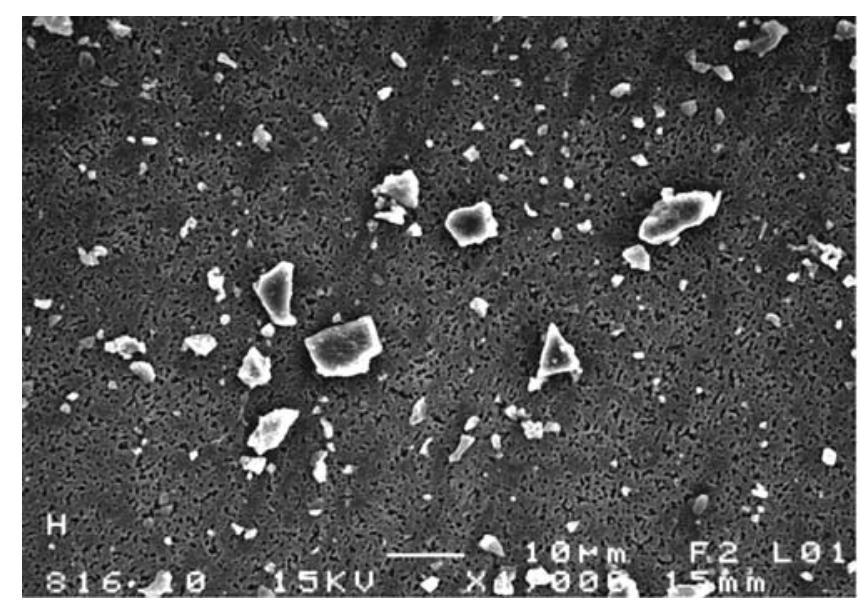

Figure 1. Scanning electron microscope (SEM) photograph of Pinatubo volcanic ash. The white bar denotes $10 \mu \mathrm{m}$.

for which the electric field vectors oscillate in mutual orthogonal directions. The Stokes parameter $V$ is the difference between two oppositely circularly polarized components of the flux. A plane through the direction of propagation of the beam is chosen as a plane of reference for the Stokes parameters.

[9] If light is scattered by an ensemble of randomly oriented particles and time reciprocity applies, as is the case in our experiment, the Stokes vectors of the incident beam and the scattered beam are related by a $4 \times 4$ scattering matrix, for each scattering angle $\theta$, as follows [Van de Hulst, 1957, section 5.22],

$$
\left(\begin{array}{c}
I_{s c} \\
Q_{s c} \\
U_{s c} \\
V_{s c}
\end{array}\right)=\frac{\lambda^{2}}{4 \pi^{2} D^{2}}\left(\begin{array}{cccc}
F_{11} & F_{12} & F_{13} & F_{14} \\
F_{12} & F_{22} & F_{23} & F_{24} \\
-F_{13} & -F_{23} & F_{33} & F_{34} \\
F_{14} & F_{24} & -F_{34} & F_{44}
\end{array}\right)\left(\begin{array}{c}
I_{\text {in }} \\
Q_{i n} \\
U_{\text {in }} \\
V_{\text {in }}
\end{array}\right),
$$

where the subscripts in and $s c$ refer to the incident and scattered beam, respectively, $\lambda$ is the wavelength of the incident and scattered beam, and $D$ is the distance from the ensemble to the detector. The matrix with elements $F_{i j}$ is called the scattering matrix. Its elements depend on $\lambda$ and the scattering angle $\theta$ but not on the azimuthal angle. Here the plane of reference is the scattering plane, that is, the plane containing the beams of incident and scattered light. The elements $F_{i j}(\theta)$ contain information about the size distribution, shape, and refractive index of the scatterers. In this paper, measurements of two matrix elements are presented, $F_{11}(\theta)$ and $F_{12}(\theta)$. For unpolarized incident light, $F_{11}(\theta)$ is proportional to the flux of the scattered light and is also called scattering function or phase function. For reasons of convenience and tradition, we relate $F_{12}(\theta)$ to the flux of the scattered light and use a minus sign. Thus we use

$$
-F_{12} / F_{11}=\frac{I_{\perp}-I_{\|}}{I_{\perp}+I_{\|}}
$$

where, for unpolarized incident light, $I_{\perp}$ and $I_{\|}$represent the flux of the scattered light polarized perpendicularly and 

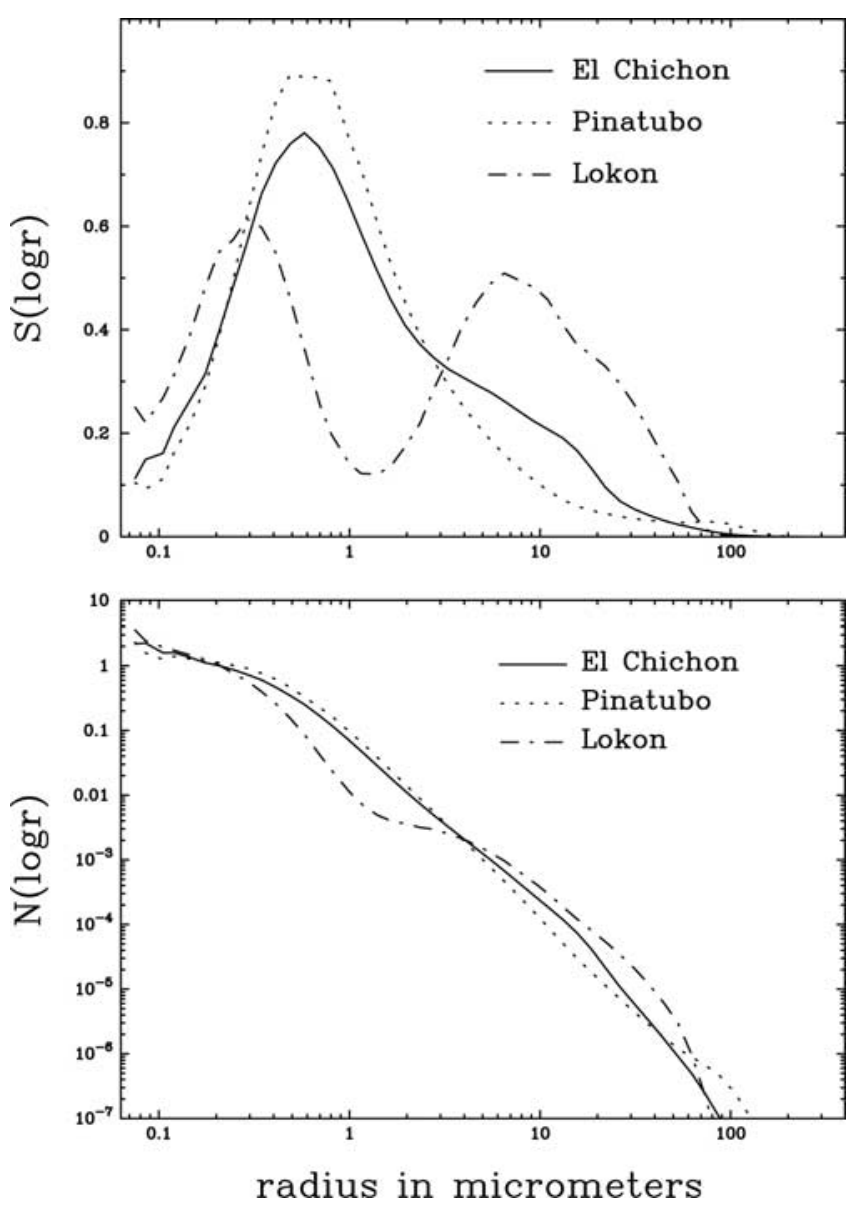

Figure 2. (top) Measured projected normalized surface area distributions and (bottom) corresponding normalized number distributions, of El Chichón, Pinatubo, and Lokon volcanic ashes. The distributions are plotted as a function of the radius in micrometers on a logarithmic scale.

parallel to the plane of reference, respectively. The ratio $-F_{12}(\theta) / F_{11}(\theta)$ equals the degree of linear polarization of the scattered light if the incident light is unpolarized and if $F_{13}(\theta)=F_{14}(\theta)=0$. Since for all mineral aerosol samples measured by Volten et al. [2001], $F_{13}(\theta)=F_{14}(\theta)=0$ within the experimental error, we assume here that for all scattering angles $F_{13}(\theta)=F_{14}(\theta)=0$ holds for all our samples.

[10] A detailed description of the experimental setup that we used to measure the scattering matrix is given by Hovenier [2000]. Briefly, we use either a $\mathrm{HeNe}$ laser $(633 \mathrm{~nm}, 5 \mathrm{~mW})$ or a $\mathrm{HeCd}$ laser $(442 \mathrm{~nm}, 40 \mathrm{~mW})$ as a light source. The laser light passes through a polarizer oriented at angle of $0^{\circ}$ between the scattering plane (horizontal plane) and its optical axis. The linearly polarized light propagates through an electro-optic modulator oriented at $-45^{\circ}$ between its optical axis and the scattering plane and measured counterclockwise when looking in the direction of propagation of the light. The modulated light is subsequently scattered by the ensemble of randomly oriented particles located in a jet stream produced by an aerosol generator. This particular configuration of the optical components allows us to measure simultaneously the scattering function $F_{11}(\theta)$ and the ratios $F_{12}(\theta) / F_{11}(\theta)$ and $F_{14}(\theta) /$ $F_{11}(\theta)$. All of the current measurements of $F_{14}$ confirm our assumption stated above that $F_{14}$ is zero within the experimental error. Other matrix elements can, in principle, be obtained with different configurations of the optical components [Hovenier, 2000]. The scattered light is detected by a photomultiplier tube which moves along a ring. A range in scattering angles is covered from $\sim 5^{\circ}$ (nearly forward scattering) to $\sim 173^{\circ}$ (nearly backward scattering). A monitor, that is, a photomultiplier placed at a fixed position, is used for normalization purposes. The

Table 1. Normalized Projected-Surface-Area Distribution $S(\log r)$ of the Volcanic Ashes Samples Studied, Where $r$ is Expressed in $\mu \mathrm{m}^{\mathrm{a}}$

\begin{tabular}{lccc}
\hline $\log r$ & El Chichón & Pinatubo & Lokon \\
\hline-1.12 & $1.13 \mathrm{E}-01$ & $1.04 \mathrm{E}-01$ & $2.50 \mathrm{E}-01$ \\
-1.07 & $1.50 \mathrm{E}-01$ & $9.20 \mathrm{E}-02$ & $2.21 \mathrm{E}-01$ \\
-0.98 & $1.62 \mathrm{E}-01$ & $1.12 \mathrm{E}-01$ & $2.68 \mathrm{E}-01$ \\
-0.92 & $2.12 \mathrm{E}-01$ & $1.63 \mathrm{E}-01$ & $3.13 \mathrm{E}-01$ \\
-0.84 & $2.63 \mathrm{E}-01$ & $2.16 \mathrm{E}-01$ & $3.88 \mathrm{E}-01$ \\
-0.76 & $3.15 \mathrm{E}-01$ & $2.91 \mathrm{E}-01$ & $4.82 \mathrm{E}-01$ \\
-0.69 & $3.93 \mathrm{E}-01$ & $3.82 \mathrm{E}-01$ & $5.49 \mathrm{E}-01$ \\
-0.61 & $4.85 \mathrm{E}-01$ & $4.95 \mathrm{E}-01$ & $5.74 \mathrm{E}-01$ \\
-0.54 & $5.70 \mathrm{E}-01$ & $6.20 \mathrm{E}-01$ & $6.14 \mathrm{E}-01$ \\
-0.46 & $6.64 \mathrm{E}-01$ & $7.37 \mathrm{E}-01$ & $5.98 \mathrm{E}-01$ \\
-0.39 & $7.24 \mathrm{E}-01$ & $8.40 \mathrm{E}-01$ & $5.49 \mathrm{E}-01$ \\
-0.31 & $7.62 \mathrm{E}-01$ & $8.94 \mathrm{E}-01$ & $4.59 \mathrm{E}-01$ \\
-0.22 & $7.56 \mathrm{E}-01$ & $8.87 \mathrm{E}-01$ & $3.44 \mathrm{E}-01$ \\
-0.15 & $7.45 \mathrm{E}-01$ & $8.89 \mathrm{E}-01$ & $2.54 \mathrm{E}-01$ \\
-0.10 & $7.32 \mathrm{E}-01$ & $8.80 \mathrm{E}-01$ & $1.99 \mathrm{E}-01$ \\
0.00 & $6.36 \mathrm{E}-01$ & $7.67 \mathrm{E}-01$ & $1.41 \mathrm{E}-01$ \\
0.06 & $5.90 \mathrm{E}-01$ & $7.11 \mathrm{E}-01$ & $1.22 \mathrm{E}-01$ \\
0.15 & $5.12 \mathrm{E}-01$ & $6.06 \mathrm{E}-01$ & $1.21 \mathrm{E}-01$ \\
0.22 & $4.58 \mathrm{E}-01$ & $5.26 \mathrm{E}-01$ & $1.36 \mathrm{E}-01$ \\
0.29 & $4.11 \mathrm{E}-01$ & $4.55 \mathrm{E}-01$ & $1.73 \mathrm{E}-01$ \\
0.37 & $3.70 \mathrm{E}-01$ & $3.88 \mathrm{E}-01$ & $2.19 \mathrm{E}-01$ \\
0.44 & $3.49 \mathrm{E}-01$ & $3.41 \mathrm{E}-01$ & $2.83 \mathrm{E}-01$ \\
0.52 & $3.24 \mathrm{E}-01$ & $2.93 \mathrm{E}-01$ & $3.44 \mathrm{E}-01$ \\
0.59 & $3.10 \mathrm{E}-01$ & $2.55 \mathrm{E}-01$ & $4.06 \mathrm{E}-01$ \\
0.67 & $2.94 \mathrm{E}-01$ & $2.18 \mathrm{E}-01$ & $4.54 \mathrm{E}-01$ \\
0.74 & $2.80 \mathrm{E}-01$ & $1.86 \mathrm{E}-01$ & $4.89 \mathrm{E}-01$ \\
0.81 & $2.64 \mathrm{E}-01$ & $1.58 \mathrm{E}-01$ & $5.09 \mathrm{E}-01$ \\
0.90 & $2.36 \mathrm{E}-01$ & $1.28 \mathrm{E}-01$ & $4.93 \mathrm{E}-01$ \\
0.98 & $2.19 \mathrm{E}-01$ & $1.07 \mathrm{E}-01$ & $4.80 \mathrm{E}-01$ \\
1.04 & $2.09 \mathrm{E}-01$ & $8.93 \mathrm{E}-02$ & $4.58 \mathrm{E}-01$ \\
1.11 & $1.93 \mathrm{E}-01$ & $7.25 \mathrm{E}-02$ & $4.13 \mathrm{E}-01$ \\
1.19 & $1.69 \mathrm{E}-01$ & $5.96 \mathrm{E}-02$ & $3.73 \mathrm{E}-01$ \\
1.27 & $1.33 \mathrm{E}-01$ & $5.10 \mathrm{E}-02$ & $3.52 \mathrm{E}-01$ \\
1.34 & $9.56 \mathrm{E}-02$ & $4.46 \mathrm{E}-02$ & $3.29 \mathrm{E}-01$ \\
1.42 & $6.82 \mathrm{E}-02$ & $3.88 \mathrm{E}-02$ & $2.94 \mathrm{E}-01$ \\
1.50 & $5.29 \mathrm{E}-02$ & $3.46 \mathrm{E}-02$ & $2.54 \mathrm{E}-01$ \\
1.57 & $4.18 \mathrm{E}-02$ & $3.17 \mathrm{E}-02$ & $2.08 \mathrm{E}-01$ \\
1.64 & $3.20 \mathrm{E}-02$ & $2.92 \mathrm{E}-02$ & $1.57 \mathrm{E}-01$ \\
1.72 & $2.39 \mathrm{E}-02$ & $2.71 \mathrm{E}-02$ & $1.09 \mathrm{E}-01$ \\
1.80 & $1.79 \mathrm{E}-02$ & $2.81 \mathrm{E}-02$ & $4.74 \mathrm{E}-02$ \\
1.87 & $1.18 \mathrm{E}-02$ & $2.92 \mathrm{E}-02$ & $1.37 \mathrm{E}-02$ \\
1.95 & $7.04 \mathrm{E}-03$ & $2.81 \mathrm{E}-02$ & $2.75 \mathrm{E}-03$ \\
2.02 & $3.68 \mathrm{E}-03$ & $2.24 \mathrm{E}-02$ & $3.57 \mathrm{E}-04$ \\
2.10 & $1.80 \mathrm{E}-03$ & $1.41 \mathrm{E}-02$ & 0 \\
2.17 & $8.28 \mathrm{E}-04$ & $6.24 \mathrm{E}-03$ & 0 \\
2.25 & $3.59 \mathrm{E}-04$ & $1.72 \mathrm{E}-03$ & 0 \\
2.32 & $1.41 \mathrm{E}-04$ & $2.79 \mathrm{E}-04$ & 0 \\
2.40 & $5.09 \mathrm{E}-05$ & $3.13 \mathrm{E}-05$ & 0 \\
2.47 & $2.85 \mathrm{E}-05$ & 0 & 0 \\
2.55 & $1.20 \mathrm{E}-05$ & 0 & 0 \\
\hline & 601 & $050-1$ & \\
\hline
\end{tabular}

${ }^{\mathrm{a}}$ The values correspond to the curves presented in Figure 2 for El Chichón, Pinatubo, and Lokon volcanic ashes. Read 1.13E-01 as $1.13 \times 10^{1}$ 
Table 2. Normalized Number Distributions $N(\log r)$, of the Volcanic Ashes Studied, Where $r$ is Expressed in $\mu \mathrm{m}^{\mathrm{a}}$

\begin{tabular}{|c|c|c|c|}
\hline $\log r$ & El Chichón & Pinatubo & Lokon \\
\hline-1.12 & $2.18 \mathrm{E}+00$ & $2.30 \mathrm{E}+00$ & $3.54 \mathrm{E}+00$ \\
\hline-1.07 & $2.24 \mathrm{E}+00$ & $1.58 \mathrm{E}+00$ & $2.43 \mathrm{E}+00$ \\
\hline-0.98 & $1.59 \mathrm{E}+00$ & $1.26 \mathrm{E}+00$ & $1.94 \mathrm{E}+00$ \\
\hline-0.92 & $1.59 \mathrm{E}+00$ & $1.40 \mathrm{E}+00$ & $1.73 \mathrm{E}+00$ \\
\hline-0.84 & $1.35 \mathrm{E}+00$ & $1.27 \mathrm{E}+00$ & $1.47 \mathrm{E}+00$ \\
\hline-0.76 & $1.11 \mathrm{E}+00$ & $1.18 \mathrm{E}+00$ & $1.26 \mathrm{E}+00$ \\
\hline-0.69 & $1.01 \mathrm{E}+00$ & $1.13 \mathrm{E}+00$ & $1.04 \mathrm{E}+00$ \\
\hline-0.61 & $8.74 \mathrm{E}-01$ & $1.02 \mathrm{E}+00$ & $7.62 \mathrm{E}-01$ \\
\hline-0.54 & $7.34 \mathrm{E}-01$ & $9.14 \mathrm{E}-01$ & $5.82 \mathrm{E}-01$ \\
\hline-0.46 & $6.03 \mathrm{E}-01$ & $7.67 \mathrm{E}-01$ & $4.00 \mathrm{E}-01$ \\
\hline-0.39 & $4.66 \mathrm{E}-01$ & $6.19 \mathrm{E}-01$ & $2.60 \mathrm{E}-01$ \\
\hline-0.31 & $3.43 \mathrm{E}-01$ & $4.61 \mathrm{E}-01$ & $1.52 \mathrm{E}-01$ \\
\hline-0.22 & $2.27 \mathrm{E}-01$ & $3.05 \mathrm{E}-01$ & $7.61 \mathrm{E}-02$ \\
\hline-0.15 & $1.65 \mathrm{E}-01$ & $2.25 \mathrm{E}-01$ & $4.14 \mathrm{E}-02$ \\
\hline-0.10 & $1.24 \mathrm{E}-01$ & $1.70 \mathrm{E}-01$ & $2.48 \mathrm{E}-02$ \\
\hline 0.00 & $6.88 \mathrm{E}-02$ & $9.50 \mathrm{E}-02$ & $1.12 \mathrm{E}-02$ \\
\hline 0.06 & $4.83 \mathrm{E}-02$ & $6.66 \mathrm{E}-02$ & $7.37 \mathrm{E}-03$ \\
\hline 0.15 & $2.83 \mathrm{E}-02$ & $3.83 \mathrm{E}-02$ & $4.90 \mathrm{E}-03$ \\
\hline 0.22 & $1.82 \mathrm{E}-02$ & $2.39 \mathrm{E}-02$ & $3.99 \mathrm{E}-03$ \\
\hline 0.29 & $1.17 \mathrm{E}-02$ & $1.48 \mathrm{E}-02$ & $3.63 \mathrm{E}-03$ \\
\hline 0.37 & $7.25 \mathrm{E}-03$ & $8.70 \mathrm{E}-03$ & $3.17 \mathrm{E}-03$ \\
\hline 0.44 & $4.99 \mathrm{E}-03$ & $5.59 \mathrm{E}-03$ & $2.98 \mathrm{E}-03$ \\
\hline 0.52 & $3.22 \mathrm{E}-03$ & $3.33 \mathrm{E}-03$ & $2.52 \mathrm{E}-03$ \\
\hline 0.59 & $2.20 \mathrm{E}-03$ & $2.08 \mathrm{E}-03$ & $2.13 \mathrm{E}-03$ \\
\hline 0.67 & $1.47 \mathrm{E}-03$ & $1.25 \mathrm{E}-03$ & $1.67 \mathrm{E}-03$ \\
\hline 0.74 & $1.00 \mathrm{E}-03$ & $7.63 \mathrm{E}-04$ & $1.29 \mathrm{E}-03$ \\
\hline 0.81 & $6.75 \mathrm{E}-04$ & $4.64 \mathrm{E}-04$ & $9.61 \mathrm{E}-04$ \\
\hline 0.90 & $4.00 \mathrm{E}-04$ & $2.48 \mathrm{E}-04$ & $6.15 \mathrm{E}-04$ \\
\hline 0.98 & $2.62 \mathrm{E}-04$ & $1.46 \mathrm{E}-04$ & $4.24 \mathrm{E}-04$ \\
\hline 1.04 & $1.87 \mathrm{E}-04$ & $9.14 \mathrm{E}-05$ & $3.02 \mathrm{E}-04$ \\
\hline 1.11 & $1.24 \mathrm{E}-04$ & $5.32 \mathrm{E}-05$ & $1.95 \mathrm{E}-04$ \\
\hline 1.19 & $7.59 \mathrm{E}-05$ & $3.07 \mathrm{E}-05$ & $1.24 \mathrm{E}-04$ \\
\hline 1.27 & $4.21 \mathrm{E}-05$ & $1.84 \mathrm{E}-05$ & $8.19 \mathrm{E}-05$ \\
\hline 1.34 & $2.14 \mathrm{E}-05$ & $1.14 \mathrm{E}-05$ & $5.43 \mathrm{E}-05$ \\
\hline 1.42 & $1.05 \mathrm{E}-05$ & $6.85 \mathrm{E}-06$ & $3.33 \mathrm{E}-05$ \\
\hline 1.50 & $5.77 \mathrm{E}-06$ & $4.33 \mathrm{E}-06$ & $2.04 \mathrm{E}-05$ \\
\hline 1.57 & $3.31 \mathrm{E}-06$ & $2.87 \mathrm{E}-06$ & $1.21 \mathrm{E}-05$ \\
\hline 1.64 & $1.79 \mathrm{E}-06$ & $1.87 \mathrm{E}-06$ & $6.45 \mathrm{E}-06$ \\
\hline 1.72 & $9.39 \mathrm{E}-07$ & $1.22 \mathrm{E}-06$ & $3.15 \mathrm{E}-06$ \\
\hline 1.80 & $4.96 \mathrm{E}-07$ & $8.91 \mathrm{E}-07$ & $9.67 \mathrm{E}-07$ \\
\hline 1.87 & $2.30 \mathrm{E}-07$ & $6.52 \mathrm{E}-07$ & $1.97 \mathrm{E}-07$ \\
\hline 1.95 & $9.73 \mathrm{E}-08$ & $4.44 \mathrm{E}-07$ & $2.80 \mathrm{E}-08$ \\
\hline 2.02 & $3.61 \mathrm{E}-08$ & $2.52 \mathrm{E}-07$ & $2.58 \mathrm{E}-09$ \\
\hline 2.10 & $1.25 \mathrm{E}-08$ & $1.12 \mathrm{E}-07$ & 0 \\
\hline 2.17 & $4.06 \mathrm{E}-09$ & $3.51 \mathrm{E}-08$ & 0 \\
\hline 2.25 & $1.24 \mathrm{E}-09$ & $6.82 \mathrm{E}-09$ & 0 \\
\hline 2.32 & $3.47 \mathrm{E}-10$ & $7.85 \mathrm{E}-10$ & 0 \\
\hline 2.40 & $8.81 \mathrm{E}-11$ & $6.20 \mathrm{E}-11$ & 0 \\
\hline 2.47 & $3.49 \mathrm{E}-11$ & 0 & 0 \\
\hline 2.55 & $1.04 \mathrm{E}-11$ & 0 & 0 \\
\hline
\end{tabular}

${ }^{\mathrm{a}}$ The values correspond to the curves presented in Figure 2 for El Chichón, Pinatubo, and Lokon volcanic ashes.

procedure during the measurements is as follows: the aerosol jet in the scattering center is produced by an aerosol generator, which consists of a reservoir, a brush, and an airflow control. The reservoir is filled with the aerosol sample, which is pushed upward against a rotating brush. An airflow blows the particles from the brush through a tube in the scattering zone, where the light from the laser beam is scattered by the aerosols. In order to investigate whether the shape of the particles had changed after passing the aerosol generator, we put a glass plate under the aerosol jet to recover the sample as it was measured during the experiment. We look at it through a microscope and compare the particles with particles of the same sample that are not used for the experiment. In all cases the particles before and after the experiment did not look different.

[11] Errors in the measured matrix elements originate mainly from fluctuations in the measured signal or signals. For each data point at a given scattering angle, 720 measurements are conducted in $\sim 2 \mathrm{~s}$. The values obtained for the measured matrix elements or combinations of matrix elements are the average of several data points (about five or more), and the corresponding experimental error is the standard deviation of the mean value [see, also, Volten et al., 2001].

[12] Measurements with water droplets were done in order to test the setup. Since the water droplets had spherical shapes, we could compare the experimental results with those obtained from Mie calculations. We found excellent agreement over the entire angle range measured for all scattering matrix elements. The results of the experiments and calculations for water droplets have been published by Volten et al. [2001].

\section{Characterization of the Samples}

\subsection{Origin and Shapes}

[13] Volcanic ashes show a wide variety of irregular shapes. As an example, we present in Figure 1, a Scanning Electronic Microscope (SEM) picture of Pinatubo volcanic ash. It should be noted that the SEM picture is not necessarily representative for the size distribution; for that purpose, we refer to Figure 2. We refer to Gooding and Clanton [1983] and Volten et al. [2001] for SEM photographs of El Chichón and Lokon volcanic ashes, respectively. The SEM photographs of Pinatubo and Lokon samples pertain to the same sample as used for our measurements.

\subsubsection{El Chichón}

[14] El Chichón is located in an isolated part of the Chiapas region in Mexico $\left(33^{\circ} \mathrm{N}, 93.2^{\circ} \mathrm{W}\right)$. During late March and early April 1982, El Chichón underwent a series of violent explosions, which injected a massive amount of gas and particles into the stratosphere. The resulting change in the visible optical thickness of the atmosphere, which was almost entirely due to the aerosol component, was comparable to the changes caused by the largest volcanic clouds of the last century [DeLuisi et al., 1983]. Our sample of El Chichón ash was carefully collected within 24 hours of the eruption within a few kilometers of the vent [Clarke et al., 1983].

\subsubsection{Pinatubo}

[15] The Mt. Pinatubo volcano is located at $15.13^{\circ} \mathrm{N}$, $120.35^{\circ} \mathrm{E}$, in Luzon, Philippines. The eruption of this

Table 3. Overview of the $r_{\text {eff }}$ and $v_{\text {eff }}$ of the Volcanic Ashes Studied $^{\text {a }}$

\begin{tabular}{lcccc}
\hline \multicolumn{1}{c}{ Sample } & \multirow{2}{*}{$r_{\text {eff }}, \mu \mathrm{m}$} & $v_{\text {eff }}$ & \multicolumn{2}{c}{ Steepness } \\
\cline { 3 - 5 } & & & $442 \mathrm{~nm}$ & $633 \mathrm{~nm}$ \\
\hline El Chichón & 3.2 & 5.4 & - & 168 \\
Pinatubo & 3.0 & 12.3 & 234 & 232 \\
Lokon & 7.1 & 2.6 & 116 & 125 \\
\hline
\end{tabular}

${ }^{\mathrm{a}}$ Values of the steepness of the corresponding scattering functions (see section 4.1) are also given. 

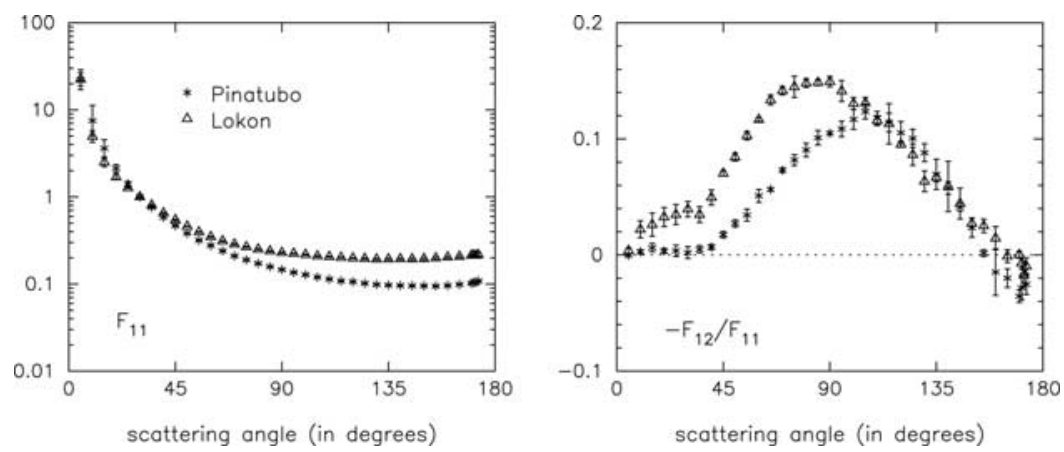

Figure 3. (left) Measured phase functions and (right) degree of linear polarization for unpolarized incident light as functions of the scattering angle for Pinatubo (asterisks) and Lokon (triangles) volcanic ashes at $442 \mathrm{~nm}$ together with their error bars. In case no error bars are shown, they are smaller than the symbols.

volcano on 15 June 1991 produced the largest volcanic aerosol haze in the twentieth century. Pinatubo sent massive amounts of gas and dust to heights of more than $25 \mathrm{~km}$. Our sample of Pinatubo particles was collected after the 1991 eruption from the ground at a distance of several kilometers from the volcano.

\subsubsection{Lokon}

[16] The Lokon volcano is located at $1.36^{\circ} \mathrm{N}, 124.79^{\circ} \mathrm{E}$, in northern Sulawesi, Indonesia. It is one the most active volcanos of Sulawesi. More than a dozen moderate eruptions have been documented since the early 19th century. Intermittent gas and ash eruptions have been reported as from 1969 [Volcanological Survey of Indonesia, 1986]. Our Lokon ash sample was collected from the ground at a distance of a few kilometers from the volcano within a day after a minor eruption in 1996.

\subsection{Particle Sizes}

[17] The projected surface area distributions of our ash samples have been measured by using a Fritsch laser particle sizer [Konert and Vandenberghe, 1997]. Figure 2 (top) shows normalized projected-surface-area distributions, $S(\log r)$, as functions of $r$ in micrometers on a logarithmic scale for the El Chichón, Pinatubo, and Lokon volcanic ashes. Here $r$ is the radius of a projected surface equivalent sphere and $S(\log r) d \log r$ gives the relative contribution by equivalent spheres in the interval $d \log r$ to the total projected surface area per unit volume. In Figure 2 (bottom) the corresponding normalized number

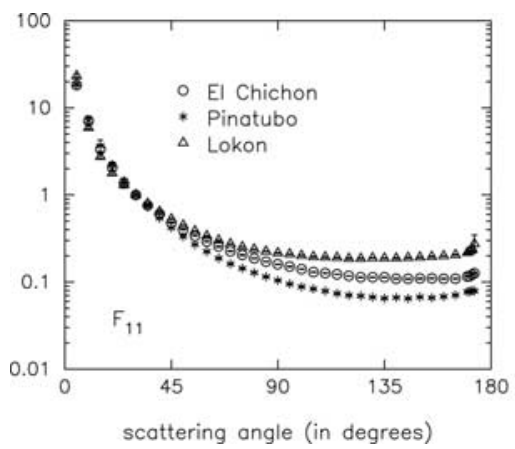

distributions, $N(\log r)$ are presented, since these are often used in calculations and reported in the literature. In Tables 1 and 2 we present the normalized projected-surface-area and normalized number distributions, respectively, as functions of $\log r$ corresponding to the curves presented in Figure 2.

[18] Values of the effective radius, $r_{\text {eff }}$, and effective variance, $v_{\text {eff, }}$ of each sample are given in Table 3 . These two parameters are defined as follows:

$$
\begin{gathered}
r_{\mathrm{eff}}=\frac{\int_{0}^{\infty} r \pi r^{2} n(r) d r}{\int_{0}^{\infty} \pi r^{2} n(r) d r} \\
v_{\mathrm{eff}}=\frac{\int_{0}^{\infty}\left(r-r_{\mathrm{eff}}\right)^{2} \pi r^{2} n(r) d r}{r_{\mathrm{eff}}^{2} \int_{0}^{\infty} \pi r^{2} n(r) d r},
\end{gathered}
$$

where $n(r) \mathrm{d} r$ is the fraction of the total number of projected surface equivalent spheres with radii in the size range $[r, r+d r]$ per unit volume of space [Hansen and Travis, 1974]. Here, $n(r)$ is computed from $N(\log r)$. For further information on the size distributions [see, e.g., Volten et al., 2001].

\subsection{Refractive Indices and Composition}

[19] In this section we present approximated values of the complex refractive indices $(m=n-i k)$ of our volcanic ashes samples.

[20] The real parts of the refractive index, $n$, of silicate glasses with compositions similar to volcanic ashes, vary

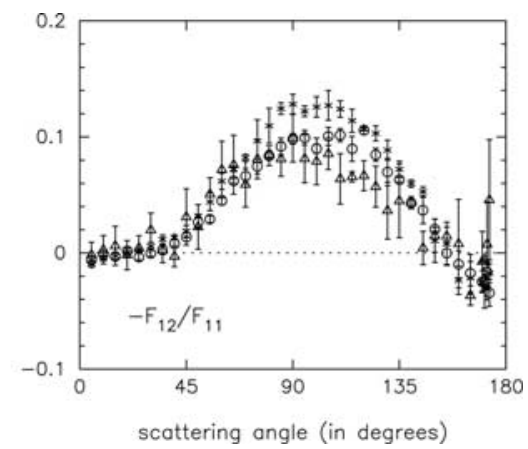

Figure 4. Same as Figure 3, but at $633 \mathrm{~nm}$. Circles, asterisks, and triangles correspond to measured results for El Chichón, Pinatubo, and Lokon volcanic ashes, respectively. 
between 1.5 and 1.6 for visible and near ultraviolet wavelengths [Patterson, 1981].

[21] Volcanic silicate ashes show a range of color from nearly white to dark grey, with corresponding differences in the imaginary part of the refractive index at visible wavelengths. Patterson et al. [1983] measured the complex refractive index of several samples of El Chichón ash. They found values of the imaginary part of the refractive index, $k$, around $\sim 1.0 \times 10^{-3}$ for their samples and very little wavelength dependence between 450 and $650 \mathrm{~nm}$. Clarke et al. [1983] obtained a value of the imaginary part of the refractive index of our sample of El Chichón ash of 0.0034 at $550 \mathrm{~nm}$. Since there is little difference between the colors of the Pinatubo and El Chichón samples (both are light grey), we assume that the imaginary parts of the refractive indices of these samples have nearly the same value, with a similar wavelength dependence. In contrast, Lokon ash shows a dark grey color. Patterson [1981] reports measurements of the imaginary part of the refractive index for Fuego ash which also exhibits a dark grey color. According to this author, Fuego ash presents a stronger wavelength dependence than our El Chichón sample, with values of $k$ ranging from $\sim 0.035$ at $450 \mathrm{~nm}$ to $\sim 0.02$ at $650 \mathrm{~nm}$. On the basis of the similarity in color of Lokon and Fuego ash, we assume the imaginary parts of their refractive indices to be also very similar.

\section{Experimental Results and Discussion}

[22] In Figures 3 and 4 we present the phase functions and degrees of linear polarization for unpolarized incident light of the samples discussed in section 3 , as functions of the scattering angle at 442 and $633 \mathrm{~nm}$, respectively. All scattering functions or phase functions, $F_{11}(\theta)$, considered in this paper, are shown on a logarithmic scale. Owing to the lack of measurements for scattering angles in the ranges $0^{\circ}-5^{\circ}$ and $173^{\circ}-180^{\circ}$, we cannot use the standard normalization, which requires the average of the phase function over all directions to be unity. Instead we normalize $F_{11}(\theta)$ to 1 at $30^{\circ}$. The experimental errors are indicated by error bars. When no error bar is shown, the value for the standard deviation of the mean value is smaller than the symbol plotted.

[23] As shown in Figures 3 and 4, the phase functions, $F_{11}(\theta)$, follow the general trends presented by irregularly shaped mineral particles, i.e., a strong forward peak and a flat shape for side and backscattering [Mishchenko et al., 2000b; Muñoz et al., 2000; Volten et al., 2001]. Looking in more detail, we see some differences between the scattering functions of the three volcanic ashes. Although the shapes of these functions are very similar, the steepness of the $F_{11}(\theta)$ curves, defined as the measured maximum value of $F_{11}(\theta)$ divided by the measured minimum value over the scattering angle range $5^{\circ}-173^{\circ}$, varies from 116 to 234 (see Table 3).

[24] As mentioned before, polarization data are important for reliable retrievals of aerosol characteristics. In Figures 3 and 4, we present measured values of $-F_{12}(\theta) /$ $F_{11}(\theta)$, which in our case equals the degree of linear polarization of the scattered light for unpolarized incident light, at 442 and $633 \mathrm{~nm}$, respectively. The measured results for the three volcanic ashes in Figures 3 and 4,
Table 4. Measured Scattering Functions $F_{11}$ and $-F_{12} / F_{11}$ as Functions of Scattering Angle $\theta$ (in Degrees), Corresponding to Curves Presented in Figure 3 for Pinatubo and Lokon Volcanic Ashes at $442 \mathrm{~nm}^{\mathrm{a}}$

\begin{tabular}{rrrrr}
\hline$\theta$ & $F_{11}$ at $442 \mathrm{~nm}$ & \multicolumn{1}{c}{$-F_{12} / F_{11}$ at $442 \mathrm{~nm}$} \\
\cline { 2 - 5 } & Pinatubo & Lokon & Pinatubo & Lokon \\
\hline 5 & $22.238 \pm 0.814$ & $22.423 \pm 0.775$ & $-0.000 \pm 0.001$ & $0.004 \pm 0.002$ \\
10 & $7.531 \pm 0.274$ & $4.945 \pm 0.067$ & $0.003 \pm 0.002$ & $0.022 \pm 0.007$ \\
15 & $3.613 \pm 0.099$ & $2.507 \pm 0.052$ & $0.006 \pm 0.004$ & $0.026 \pm 0.010$ \\
20 & $2.125 \pm 0.043$ & $1.695 \pm 0.025$ & $0.004 \pm 0.002$ & $0.033 \pm 0.008$ \\
25 & $1.418 \pm 0.023$ & $1.272 \pm 0.007$ & $0.004 \pm 0.005$ & $0.035 \pm 0.009$ \\
30 & 1.000 & 1.000 & $0.002 \pm 0.005$ & $0.039 \pm 0.007$ \\
35 & $0.759 \pm 0.012$ & $0.805 \pm 0.003$ & $0.005 \pm 0.003$ & $0.035 \pm 0.007$ \\
40 & $0.586 \pm 0.012$ & $0.653 \pm 0.009$ & $0.007 \pm 0.002$ & $0.050 \pm 0.007$ \\
45 & $0.468 \pm 0.006$ & $0.545 \pm 0.007$ & $0.017 \pm 0.002$ & $0.070 \pm 0.002$ \\
50 & $0.382 \pm 0.008$ & $0.461 \pm 0.004$ & $0.027 \pm 0.003$ & $0.084 \pm 0.003$ \\
55 & $0.318 \pm 0.003$ & $0.396 \pm 0.005$ & $0.034 \pm 0.005$ & $0.103 \pm 0.004$ \\
60 & $0.277 \pm 0.008$ & $0.348 \pm 0.006$ & $0.051 \pm 0.006$ & $0.117 \pm 0.002$ \\
65 & $0.240 \pm 0.009$ & $0.312 \pm 0.007$ & $0.056 \pm 0.001$ & $0.134 \pm 0.004$ \\
70 & $0.210 \pm 0.008$ & $0.287 \pm 0.007$ & $0.073 \pm 0.002$ & $0.141 \pm 0.004$ \\
75 & $0.189 \pm 0.005$ & $0.267 \pm 0.006$ & $0.082 \pm 0.005$ & $0.145 \pm 0.009$ \\
80 & $0.172 \pm 0.005$ & $0.251 \pm 0.008$ & $0.090 \pm 0.006$ & $0.148 \pm 0.004$ \\
85 & $0.158 \pm 0.004$ & $0.239 \pm 0.009$ & $0.101 \pm 0.006$ & $0.148 \pm 0.003$ \\
90 & $0.146 \pm 0.003$ & $0.230 \pm 0.008$ & $0.105 \pm 0.001$ & $0.149 \pm 0.004$ \\
95 & $0.136 \pm 0.004$ & $0.224 \pm 0.006$ & $0.109 \pm 0.007$ & $0.141 \pm 0.009$ \\
100 & $0.128 \pm 0.003$ & $0.218 \pm 0.006$ & $0.117 \pm 0.009$ & $0.130 \pm 0.005$ \\
105 & $0.120 \pm 0.002$ & $0.210 \pm 0.007$ & $0.123 \pm 0.006$ & $0.131 \pm 0.005$ \\
110 & $0.114 \pm 0.003$ & $0.206 \pm 0.006$ & $0.118 \pm 0.005$ & $0.116 \pm 0.004$ \\
115 & $0.109 \pm 0.002$ & $0.202 \pm 0.005$ & $0.114 \pm 0.008$ & $0.113 \pm 0.017$ \\
120 & $0.106 \pm 0.002$ & $0.198 \pm 0.005$ & $0.105 \pm 0.010$ & $0.095 \pm 0.003$ \\
125 & $0.102 \pm 0.003$ & $0.196 \pm 0.008$ & $0.100 \pm 0.008$ & $0.086 \pm 0.009$ \\
130 & $0.099 \pm 0.003$ & $0.193 \pm 0.010$ & $0.088 \pm 0.008$ & $0.064 \pm 0.009$ \\
135 & $0.097 \pm 0.003$ & $0.194 \pm 0.011$ & $0.069 \pm 0.013$ & $0.067 \pm 0.003$ \\
140 & $0.096 \pm 0.001$ & $0.194 \pm 0.011$ & $0.058 \pm 0.005$ & $0.059 \pm 0.022$ \\
145 & $0.095 \pm 0.002$ & $0.194 \pm 0.013$ & $0.041 \pm 0.003$ & $0.044 \pm 0.013$ \\
150 & $0.095 \pm 0.002$ & $0.195 \pm 0.014$ & $0.024 \pm 0.008$ & $0.027 \pm 0.005$ \\
155 & $0.095 \pm 0.003$ & $0.199 \pm 0.012$ & $0.002 \pm 0.003$ & $0.025 \pm 0.006$ \\
160 & $0.096 \pm 0.004$ & $0.203 \pm 0.013$ & $-0.015 \pm 0.020$ & $0.015 \pm 0.010$ \\
165 & $0.099 \pm 0.003$ & $0.207 \pm 0.013$ & $-0.020 \pm 0.008$ & $-0.001 \pm 0.005$ \\
170 & $0.102 \pm 0.003$ & $0.213 \pm 0.015$ & $-0.035 \pm 0.005$ & $0.000 \pm 0.003$ \\
171 & $0.104 \pm 0.004$ & $0.214 \pm 0.017$ & $-0.028 \pm 0.011$ & $-0.007 \pm 0.005$ \\
172 & $0.105 \pm 0.006$ & $0.213 \pm 0.024$ & $-0.014 \pm 0.010$ & $-0.017 \pm 0.010$ \\
173 & $0.108 \pm 0.005$ & $0.217 \pm 0.024$ & $-0.025 \pm 0.009$ & $-0.010 \pm 0.007$ \\
\hline & & & &
\end{tabular}

${ }^{\mathrm{a}}$ The experimental errors are also given.

resemble the typical shape of irregular mineral particles, namely, a maximum at side scattering angles and a negative branch for directions close to the backward direction. However, there are differences in the heights of the maxima, ranging at $442 \mathrm{~nm}$ from $0.123 \pm 0.006$ for Pinatubo to $0.149 \pm 0.004$ for Lokon and at $633 \mathrm{~nm}$ from $0.099 \pm 0.021$ for Lokon via $0.106 \pm 0.004$ for El Chichón, to $0.128 \pm 0.009$ for Pinatubo. In addition, the shape of the polarization curve for Lokon ash at $442 \mathrm{~nm}$ (see Figure 3) differs from the shape of all other polarization curves by showing a higher degree of linear polarization for scattering angles up to $\sim 100^{\circ}$.

[25] In Tables 4 and 5 the measured values of $F_{11}(\theta)$ and $-F_{12}(\theta) / F_{11}(\theta)$ at 442 and $633 \mathrm{~nm}$ are given that correspond to the data presented in Figures 3 and 4, respectively. As mentioned before, we performed new measurements for Pinatubo volcanic ash at $633 \mathrm{~nm}$, mainly because the scatter in the measured values of $-F_{12}(\theta) / F_{11}(\theta)$ was fairly large in the measurements reported in Volten et al. [2001]. If we compare the tabulated values reported by Volten [2001] for $F_{11}(\theta)$ and $-F_{12}(\theta) / F_{11}(\theta)$ for Pinatubo ash at $633 \mathrm{~nm}$ with 
Table 5. Measured Scattering Functions $F_{11}$ and $-F_{12} / F_{11}$ as Functions of Scattering Angle $\theta$ (in Degrees), Corresponding to Curves Presented in Figure 4 for El Chichón, Lokon, and Pinatubo Volcanic Ashes at $633 \mathrm{~nm}^{\mathrm{a}}$

\begin{tabular}{|c|c|c|c|c|c|c|}
\hline \multirow[t]{2}{*}{$\theta$} & \multicolumn{3}{|c|}{$F_{11}$ at $633 \mathrm{~nm}$} & \multicolumn{3}{|c|}{$-F_{12} / F_{11}$ at $633 \mathrm{~nm}$} \\
\hline & El Chichón & Pinatubo & Lokon & El Chichón & Pinatubo & Lokon \\
\hline 5 & $18.301 \pm 2.061$ & $18.312 \pm 1.968$ & $23.283 \pm 1.338$ & $-0.006 \pm 0.001$ & $-0.010 \pm 0.003$ & $-0.001 \pm 0.011$ \\
\hline 10 & $7.040 \pm 0.316$ & $6.923 \pm 0.390$ & $5.934 \pm 0.166$ & $-0.001 \pm 0.002$ & $-0.004 \pm 0.002$ & $0.003 \pm 0.012$ \\
\hline 15 & $3.339 \pm 0.119$ & $3.553 \pm 0.133$ & $2.759 \pm 0.019$ & $-0.003 \pm 0.003$ & $-0.003 \pm 0.003$ & $0.006 \pm 0.017$ \\
\hline 20 & $2.062 \pm 0.032$ & $2.168 \pm 0.057$ & $1.788 \pm 0.022$ & $0.002 \pm 0.002$ & $0.000 \pm 0.004$ & $-0.002 \pm 0.013$ \\
\hline 25 & $1.359 \pm 0.019$ & $1.410 \pm 0.040$ & $1.301 \pm 0.019$ & $-0.004 \pm 0.003$ & $0.002 \pm 0.002$ & $0.004 \pm 0.011$ \\
\hline 30 & 1.000 & 1.000 & 1.000 & $-0.000 \pm 0.003$ & $0.006 \pm 0.003$ & $0.020 \pm 0.015$ \\
\hline 35 & $0.761 \pm 0.003$ & $0.741 \pm 0.008$ & $0.794 \pm 0.007$ & $0.003 \pm 0.004$ & $0.012 \pm 0.004$ & $0.002 \pm 0.011$ \\
\hline 40 & $0.604 \pm 0.005$ & $0.562 \pm 0.018$ & $0.644 \pm 0.006$ & $0.008 \pm 0.004$ & $0.014 \pm 0.002$ & $-0.003 \pm 0.009$ \\
\hline 45 & $0.478 \pm 0.005$ & $0.437 \pm 0.016$ & $0.530 \pm 0.005$ & $0.014 \pm 0.000$ & $0.019 \pm 0.005$ & $0.031 \pm 0.024$ \\
\hline 50 & $0.400 \pm 0.003$ & $0.356 \pm 0.022$ & $0.449 \pm 0.004$ & $0.026 \pm 0.005$ & $0.032 \pm 0.001$ & $0.023 \pm 0.019$ \\
\hline 55 & $0.339 \pm 0.003$ & $0.294 \pm 0.022$ & $0.386 \pm 0.004$ & $0.029 \pm 0.003$ & $0.044 \pm 0.008$ & $0.051 \pm 0.014$ \\
\hline 60 & $0.292 \pm 0.005$ & $0.248 \pm 0.022$ & $0.339 \pm 0.004$ & $0.045 \pm 0.004$ & $0.062 \pm 0.007$ & $0.072 \pm 0.024$ \\
\hline 65 & $0.256 \pm 0.007$ & $0.211 \pm 0.022$ & $0.302 \pm 0.004$ & $0.062 \pm 0.002$ & $0.072 \pm 0.002$ & $0.076 \pm 0.025$ \\
\hline 70 & $0.227 \pm 0.006$ & $0.185 \pm 0.022$ & $0.274 \pm 0.004$ & $0.066 \pm 0.006$ & $0.082 \pm 0.003$ & $0.059 \pm 0.020$ \\
\hline 75 & $0.205 \pm 0.006$ & $0.163 \pm 0.018$ & $0.253 \pm 0.004$ & $0.075 \pm 0.006$ & $0.097 \pm 0.018$ & $0.081 \pm 0.017$ \\
\hline 80 & $0.187 \pm 0.004$ & $0.147 \pm 0.018$ & $0.238 \pm 0.004$ & $0.084 \pm 0.009$ & $0.110 \pm 0.015$ & $0.085 \pm 0.004$ \\
\hline 85 & $0.172 \pm 0.003$ & $0.132 \pm 0.016$ & $0.226 \pm 0.003$ & $0.092 \pm 0.007$ & $0.124 \pm 0.005$ & $0.081 \pm 0.015$ \\
\hline 90 & $0.159 \pm 0.004$ & $0.124 \pm 0.015$ & $0.215 \pm 0.005$ & $0.098 \pm 0.004$ & $0.128 \pm 0.009$ & $0.099 \pm 0.021$ \\
\hline 95 & $0.151 \pm 0.006$ & $0.113 \pm 0.017$ & $0.209 \pm 0.004$ & $0.099 \pm 0.006$ & $0.122 \pm 0.005$ & $0.081 \pm 0.021$ \\
\hline 100 & $0.141 \pm 0.003$ & $0.109 \pm 0.016$ & $0.202 \pm 0.005$ & $0.090 \pm 0.004$ & $0.126 \pm 0.009$ & $0.079 \pm 0.020$ \\
\hline 105 & $0.130 \pm 0.003$ & $0.102 \pm 0.015$ & $0.195 \pm 0.005$ & $0.100 \pm 0.008$ & $0.127 \pm 0.013$ & $0.085 \pm 0.014$ \\
\hline 110 & $0.126 \pm 0.004$ & $0.096 \pm 0.016$ & $0.193 \pm 0.005$ & $0.102 \pm 0.006$ & $0.124 \pm 0.007$ & $0.064 \pm 0.022$ \\
\hline 115 & $0.123 \pm 0.003$ & $0.093 \pm 0.017$ & $0.191 \pm 0.004$ & $0.090 \pm 0.011$ & $0.114 \pm 0.010$ & $0.066 \pm 0.004$ \\
\hline 120 & $0.118 \pm 0.004$ & $0.087 \pm 0.016$ & $0.186 \pm 0.007$ & $0.106 \pm 0.004$ & $0.107 \pm 0.002$ & $0.067 \pm 0.013$ \\
\hline 125 & $0.113 \pm 0.004$ & $0.085 \pm 0.014$ & $0.186 \pm 0.006$ & $0.085 \pm 0.006$ & $0.103 \pm 0.007$ & $0.057 \pm 0.018$ \\
\hline 130 & $0.113 \pm 0.004$ & $0.083 \pm 0.015$ & $0.189 \pm 0.004$ & $0.070 \pm 0.012$ & $0.089 \pm 0.009$ & $0.037 \pm 0.024$ \\
\hline 135 & $0.113 \pm 0.004$ & $0.081 \pm 0.015$ & $0.187 \pm 0.004$ & $0.063 \pm 0.002$ & $0.072 \pm 0.007$ & $0.045 \pm 0.032$ \\
\hline 140 & $0.109 \pm 0.004$ & $0.080 \pm 0.012$ & $0.188 \pm 0.008$ & $0.043 \pm 0.005$ & $0.060 \pm 0.003$ & $0.044 \pm 0.005$ \\
\hline 145 & $0.109 \pm 0.004$ & $0.079 \pm 0.014$ & $0.190 \pm 0.005$ & $0.037 \pm 0.011$ & $0.053 \pm 0.004$ & $0.004 \pm 0.014$ \\
\hline 150 & $0.110 \pm 0.006$ & $0.082 \pm 0.013$ & $0.192 \pm 0.006$ & $0.020 \pm 0.001$ & $0.011 \pm 0.019$ & $0.015 \pm 0.014$ \\
\hline 155 & $0.110 \pm 0.005$ & $0.082 \pm 0.014$ & $0.196 \pm 0.006$ & $0.000 \pm 0.010$ & $0.008 \pm 0.019$ & $0.015 \pm 0.008$ \\
\hline 160 & $0.109 \pm 0.004$ & $0.083 \pm 0.014$ & $0.200 \pm 0.004$ & $-0.010 \pm 0.012$ & $-0.023 \pm 0.012$ & $0.008 \pm 0.038$ \\
\hline 165 & $0.109 \pm 0.004$ & $0.084 \pm 0.012$ & $0.205 \pm 0.005$ & $-0.017 \pm 0.016$ & $-0.021 \pm 0.014$ & $-0.037 \pm 0.008$ \\
\hline 170 & $0.116 \pm 0.004$ & $0.089 \pm 0.011$ & $0.218 \pm 0.003$ & $-0.025 \pm 0.009$ & $-0.025 \pm 0.002$ & $-0.007 \pm 0.026$ \\
\hline 171 & $0.117 \pm 0.005$ & $0.091 \pm 0.013$ & $0.224 \pm 0.002$ & $-0.025 \pm 0.006$ & $-0.030 \pm 0.017$ & $-0.006 \pm 0.001$ \\
\hline 172 & $0.122 \pm 0.003$ & $0.093 \pm 0.012$ & $0.242 \pm 0.015$ & $-0.016 \pm 0.006$ & $-0.031 \pm 0.010$ & $0.008 \pm 0.037$ \\
\hline$\underline{173}$ & $0.127 \pm 0.004$ & $0.086 \pm 0.008$ & $0.275 \pm 0.101$ & $-0.034 \pm 0.012$ & $-0.017 \pm 0.008$ & $0.046 \pm 0.052$ \\
\hline
\end{tabular}

${ }^{\mathrm{a}}$ The experimental errors are also given.

those listed here it is evident that our error bars are generally larger. For $F_{11}(\theta)$ our table is based on 5 data points instead of 2 , and for $-F_{12}(\theta) / F_{11}(\theta)$, our table is based on 3 data points, instead of 1 , which results in larger but more reliable errors. See Volten et al. [2001, section 4.2], for details on the accuracy of the measurements. Tables 4 and 5 are included to facilitate the use of these results, for example, to evaluate calculated light scattering properties of volcanic ash particles, to constrain scattering properties of volcanic ashes that are used in radiative transfer calculations, and to retrieve characteristics of (clouds of) volcanic ash particles in the atmosphere from remote sensing data.

[26] Acknowledgments. We are indebted to R. A. West and A. D. Clarke for providing the El Chichón sample. It is a pleasure to thank G. Kuik, who provided ash from the Pinatubo volcano in the Phillipines and to F. S. Rondonuwu and his family in Sulawesi, Indonesia, who collected fresh Lokon Volcanic ash. We are grateful to several people of the Free University, particularly to J. Bouma for technical support, M. Konert for measuring the size distributions of the samples, and S. Kars for providing SEM photographs of the samples. Fruitful discussions with A. D. Clarke are gratefully acknowledged. This work was supported by the Programa Nacional del Espacio Ref: PNE-001/2000-C-01 and PNE-002/2000-C O. Muñoz thanks the European Space Agency (ESA) for a postdoctoral fellowship at the Dept. of Physics and Astronomy, Free University, Amsterdam.

\section{References}

Bernard, A., and W. I. Rose, The injection of sulfuric acid aerosol in the stratosphere by El Chichón volcano and its related hazard to international air traffic, Nat. Hazards, 3, 59-67, 1990.

Bréon, F. M., J. L. Deuzé, D. Tanré, and M. Herman, Validation of spaceborne estimates of aerosol loading from Sun photometer measurements with emphasis on polarization, J. Geophys. Res., 102, 17,187-17,195, 1997.

Chowdhary, J., B. Cairns, M. I. Mishchenko, and L. Travis, Retrieval of aerosol properties over the ocean using multispectral and multiangle photopolarimetric measurements from the Research Scanning Polarimeter, Geophys. Res. Lett., 28, 243-246, 2001

Clarke, A. D., R. J. Charlson, and J. A. Ogren, Stratospheric aerosol light absorption before and after el Chichón, Geophys. Res. Lett., 10, $1017-$ 1020, 1983.

DeLuisi, J. J., E. G. Dutton, and K. L. Coulson, Radiative features of the El Chichón volcanic stratospheric dust cloud and a cloud of unknown origin at Mauna Loa, J. Geophys. Res., 88, 6722-6769, 1983.

Goloub, P., D. Tanré, J. L. Deuzé, M. Herman, A. Marchand, and F. M. Bréon, Validation of the first algorithm applied for deriving the aerosol properties over the ocean using the POLDER/ADEOS measurements, IEEE Trans. Geosci. Remote Sens., 37, 1586-1596, 1999.

Gooding, J. L., and U. S. Clanton, El Chichón volcanic ash in the stratosphere: Particle abundances and size distributions after the 1982 eruption, Geophys. Res. Lett., 10, 1033-1036, 1983. 
Hansen, J. E., and L. D. Travis, Light scattering in planetary atmospheres, Space Sci. Rev., 16, 527-610, 1974

Hansen, J. E., W. C. Wang, and A. A. Lacis, Mount Agung eruption provides test of a global climatic perturbation, Science, 199, 10651068,1978

Hansen, J., A. Lacis, R. Ruedy, and M. Sato, Potential climate impact of Mount Pinatubo eruption, Geophys. Res. Lett., 19, 215-218, 1992.

Herman, M., J. L. Deuzé, C. Devaux, P. Goloub, F. M. Bréon, and D. Tanré, Remote sensing of aerosols over land surfaces including polarization measurements and application to POLDER measurements, J. Geophys. Res., 102, 17,039-17,049, 1997

Hovenier, J. W., Measuring scattering matrices of small particles at optical wavelengths, in Light Scattering by Nonspherical Particles, edited by M. I. Mishchenko, J. W. Hovenier, and L. D. Travis, pp. 355-365, Academic, San Diego, Calif., 2000

Hovenier, J. W., and C. V. M. van der Mee, Fundamental relationships relevant to the transfer of polarized light in a scattering atmosphere, Astron. Astrophys., 128, 1-16, 1983.

Kondratyev, K. Y., Climate Shocks: Natural and Anthropogenic, John Wiley, New York, 1988

Konert, M., and J. Vandenberghe, Comparison of laser grain size analysis with pipette and sieve analysis: A solution for the underestimation of the clay fraction, Sedimentology, 44, 532-535, 1997.

Krotkov, N. A., A. J. Krueger, and P. K. Bhartia, Ultraviolet optical model of volcanic clouds for remote sensing of ash and sulfur dioxide, J. Geophys. Res., 102, 21,891-21,904, 1997.

Krotkov, N. A., O. Torres, C. Seftor, A. J. Krueger, A. Kostinski, W. I Rose, G. J. S. Bluth, D. Schneider, and S. J. Schaefer, Comparison of TOMS and AVHRR volcanic ash retrievals from the August 1992 eruption of Mt. Spurr, Geophys. Res. Lett., 26, 455-458, 1999a.

Krotkov, N. A., D. E. Flittner, A. J. Krueger, A. Kostinski, C. Riley, W. Rose, and O. Torres, Effect of particle non-sphericity on satellite monitoring of drifting volcanic ash clouds, J. Quant. Spectrosc. Radiat. Transfer, 63, 613-630, 1999b.

Krueger, A. J., L. S. Walter, P. K. Bhartia, C. C. Schnetzler, N. A. Krtokov, I. Sprod, and G. J. S. Bluth, Volcanic sulfur dioxide measurements from the Total Ozone Mapping Spectrometer (TOMS) instruments, J. Geophys. Res., 100, 14,057-14,076, 1995.

Lacis, A. A., and M. I. Mishchenko, Climate forcing, climate sensitivity and climate response: A radiative modelling perspective on atmospheric aerosols, in Aerosol Forcing of Climate, edited by R. J. Charlson and J. Heintzenberg, pp. 11-42, John Wiley, New York, 1995.

Lambert, A., R. G. Grainger, J. J. Remedios, C. D. Rodgers, M. Corney, and F. W. Taylor, Measurements of the evolution of the Mt. Pinatubo aerosol cloud by ISAMS, Geophys. Res. Lett., 20, 1287-1290, 1993.

Mie, G., Beiträge zur Optik trüber Medien, speziell kolloidaler Metalllösungen, Ann. Phys., 25, 377-445, 1908.

Mishchenko, M. I., and L. D. Travis, Satellite retrievals of aerosol properties over the ocean using measurements of reflected sunlight: Effect of instrumental errors and aerosol absorption, J. Geophys. Res., 102, $13,543-13,554,1997$ a

Mishchenko, M. I., and L. D. Travis, Satellite retrieval of aerosol properties over the ocean using polarization as well as intensity of reflected sunlight, J. Geophys. Lett., 102, 16,989-17,013, 1997b.

Mishchenko, M. I., A. A. Lacis, B. E. Carlson, and L. D. Travis, Nonsphericity of dust-like tropospheric aerosols: Implications for aerosol remote sensing and climate modeling, J. Geophys. Lett., 22, 1077 1080, 1995

Mishchenko, M. I., I. V. Geogdzhayev, B. Cairns, W. B. Rossow, and A. A Lacis, Aerosol retrievals over the ocean by use of channels 1 and 2 AVHRR data: Sensitivity analysis and preliminary results, Appl. Opt., $38,7325-7341,1999$.

Mishchenko, M. I., J. W. Hovenier, and L. D. Travis (Eds.), Light Scattering by Nonspherical Particles, Academic, San Diego, Calif., 2000a.

Mishchenko, M. I., W. J. Wiscombe, J. W. Hovenier, and L. D. Travis, Overview of scattering by nonspherical particles, in Light Scattering by Nonspherical Particles, edited by M. I. Mishchenko, J. W. Hovenier, and L. D. Travis, pp. 29-60, Academic, San Diego, Calif., 2000b.

Muñoz, O., H. Volten, J. F. de Haan, W. Vassen, and J. W. Hovenier,
Scattering matrices of olivine and Allende meteorite particles, Astron. Astrophys., 360, 777-788, 2000.

Oberbeck, V. R., E. F. Danielsen, K. G. Snetsinger, and G. V. Ferry, Effect of the eruption of El Chichón on stratospheric aerosol size and composition, J. Geophys. Lett., 10, 1021-1024, 1983.

Patterson, E. M., Measurements of the imaginary part of the refractive index between 300 and 700 nanometers for Mount St. Helens ash, Science, 211, 836-838, 1981

Patterson, E. M., C. O. Pollard, and I. Galindo, Optical properties of the ash from El Chichón volcano, J. Geophys. Lett., 10, 317-320, 1983.

Pollack, J. B., and T. P. Ackerman, Possible effects of the El Chichón volcanic cloud on the radiation budget of the northern tropics, J. Geophys. Lett., 10, 1057-1060, 1983.

Pollack, J. B., B. T. Owen, C. Sagan, A. Summers, B. Baldwin, and W. Van Camp, Volcanic explosions and climate change: A theoretical assessment, J. Geophys. Lett., 81, 1071-1083, 1976

Pueschel, R. F., P. B. Russell, D. A. Allend, G. V. Ferry, K. G. Snetsinger, J. M. Livingston, and S. Verma, Physical and optical properties of the Pinatubo volcanic aerosol: Aircraft observations with impactors and a Sun-tracking photometer, J. Geophys. Lett., 99, 12,915-12,922, 1994.

Rao, C. R. N., L. L. Stowe, E. P. McClain, and J. Sapper, Development and application of aerosol remote sensing with AVHRR data from the NOAA satellites, in Aerosols and Climate, edited by P. Hobbs and M. P. McCormick, pp. 69-80, Deepak, Hampton, Va., 1988.

Rose, W. I., Interaction of aircraft and explosive eruption clouds: A volcanologist's perspective, AIAA J., 25, 52, 1986

Rose, W. I., and D. J. Schneider, Satellite images offer aircraft protection from volcanic ash clouds, Eos Trans $A G U, 77,529-532,1996$.

Schneider, D. J., W. I. Rose, L. R. Coke, G. J. S. Bluth, I. E. Sprod, and A. J. Krueger, Early evolution of a stratospheric volcanic eruption cloud as oberved with TOMS and AVHRR, J. Geophys. Res., 104, 4037-4050, 1999.

Sheridan, P. J., R. C. Schnell, D. J. Hofmann, and T. Deshler, Electron microscope studies of Mt. Pinatubo aerosol layers over Laramie, Wyoming during summer 1991, Geophys. Res. Lett., 19, 203-206, 1992.

Snetsinger, K. G., G. V. Ferry, P. B. Russell, R. F. Pueschel, and V. R. Oberbeck, Effects of El Chichón on stratospheric aerosols late 1982 to early 1984, J. Geophys. Res., 92, 14,761-14,771, 1987.

Stenchikov, G. L., I. Kirchner, A. Robock, H.-F. Graf, J. C. Antuña, R. G. Grainger, A. Lambert, and L. Thomason, Radiative forcing from the 1991 Mount Pinatubo volcanic eruption, J. Geophys. Res., 103, 13,837-13,857, 1998

Tsitas, S. R., and Y. L. Yung, The effect of volcanic aerosols on ultraviolet radiation in Antartica, Geophys. Res. Lett., 23, 157-160, 1996.

Van de Hulst, H. C., Light Scattering by Small Particles, John Wiley, New York, 1957.

Volcanological Survey of Indonesia, Bulletin of the Volcanological Survey of Indonesia, rep. 113, Bandung, Indonesia, 1986.

Volten, H., Light scattering by small planetary particles, Ph.D. thesis, Free Universiy, Amsterdam, 2001.

Volten, H., O. Muñoz, E. Rol, J. F. de Haan, W. Vassen, J. W. Hovenier, K. Muinonen, and T. Nousianen, Scattering matrices of mineral aerosol particles at $441.6 \mathrm{~nm}$ and $632.8 \mathrm{~nm}$, J. Geophys. Res., 106, 17,375$17,401,2001$

Wang, M., and H. R. Gordon, Estimating aerosol optical properties over the oceans with the multiangle imaging spectroradiometer: Some preliminary studies, Appl. Opt. 33, 4042-4056, 1994.

Wen, S., and W. I. Rose, Retrieval of sizes and total masses of particles in volcanic clouds using AVHRR bands 4 and 5, J. Geophys. Res., 99, $5421-5431,1994$

Winchester, L. W., Jr., G. G. Gimmestad, R. B. Wetzel, and S. M. Lee, Measurements of the phase function of natural particles, Proc. SPIE, Int. Soc. Opt. Eng., 305, 106-117, 1981.

O. Muñoz, H. Volten, J. F. de Haan, W. Vassen, and J. W. Hovenier, Department of Physics and Astronomy, Free University, De Boelelaan 1081, NL-1081 HV Amsterdam, Netherlands. (olga@iaa.es) 